\title{
Strategies to reduce potentially avoidable hospitalisations among long-term care facility residents
}

\author{
Joseph Ouslander
}

Department of Integrated Medical Science, Florida Atlantic University Charles E Schmidt College of Medicine, Boca Raton, Florida, USA

\section{Correspondence to} Dr Joseph Ouslander, Florida Atlantic University Charles E Schmidt College of Medicine, Boca Raton, FL 33431, USA; jousland@health.fau.edu

Accepted 10 May 2019 Published Online First 24 May 2019

\section{Linked}

- http://dx.doi.org/10.1136/ bmjgs-2018-009130

- http://dx.doi.org/10.1136/ bmjgs-2018-008924

- http://dx.doi.org/10.1136/ bmjqs-2019-009447

\section{Check for updates}

(c) Author(s) (or their employer(s)) 2019. No commercial re-use. See rights and permissions. Published by BMJ.

To cite: Ouslander J.

BMJ Qual Saf

2019;28:515-519.
Older people who reside in long-term care facilities (LTCFs) are frequently hospitalised. ${ }^{1}$ Hospitalisation in this vulnerable population is associated with iatrogenic conditions that often result in physical discomfort, psychological distress and functional disability, as well as excess healthcare costs. Several studies have demonstrated that a substantial proportion of these hospitalisations as well as emergency department (ED) visits that do not result in hospitalisation are potentially avoidable. ${ }^{2-12}$ Thus, efforts to reduce these potentially avoidable hospitalisations (PAH) could improve care quality and patient safety by reducing hospital and ED related complications, and save healthcare expenditures that could be used to further improve care.

The paper by Lloyd et al describes one such effort carried out in 13 residential care and 10 nursing homes in the UK involving 568 residents and 568 matched control residents who entered similar LTCFs during the study period. ${ }^{13}$ All of these residents had been in the hospital at least once in the past 2 years, so that clinical data for propensity matching would be available. The intervention included regular visits by a designated primary care physician in order to provide continuity of care, and training and support for facility staff provided by community nurses. The intervention resulted in a statistically significant reduction in $\mathrm{PAH}$, emergency hospital admissions and ED visits among the residential care home residents compared with the control group. However, there were no significant reductions in these events among residents of nursing homes and the control group. The authors suggest that these findings may have resulted from the intervention bolstering the clinical resources available to residential care homes more than it did for nursing homes, and/or had a greater potential to impact the health of the residential care home residents.

The study was well designed and had a number of important strengths, including a rigorous matching strategy that resulted in similarities between intervention and control residents in most relevant clinical characteristics as well as hospitalisation rates prior to the study; and a thorough statistical approach that included sensitivity analyses exploring higher rates of emergency admissions from residential care homes than nursing homes. These analyses help to mitigate the possibility of residual confounding, a major limitation of observational studies. There were also limitations of the study that could account for the lack of effect in nursing homes compared with residential care homes, including the relatively low rate of hospitalisation in the participating nursing homes, suggesting better care than in other nursing homes throughout the UK and the potential for a floor effect; and more community nurse training and support provided to staff in residential care homes versus nursing homes in the intervention group.

Efforts to reduce PAH and ED visits from LTCFs (including skilled nursing facilities (ie, 'nursing homes') and assisted living facilities) have been underway in USA for several years. ${ }^{14-18}$ Acute care hospitals now incur financial penalties for high rates of 30-day readmissions, as well as readmissions after hospitalisations for specific conditions, such as pneumonia, heart failure and acute coronary syndrome. New nursing home quality measures include rates of 30-day hospital readmissions and returns to the ED without admission, and related financial penalties and bonuses based on these rates will be implemented in the 
coming year. In addition, healthcare payment models that incentivise value over volume are increasingly breaking down silos between acute and postacute care organisations in order to collaborate on reducing PAH and ED visits. These payment models include Medicare managed care ('Medicare Advantage plans' or 'Medicare Part C'); bundled payments, which enable hospitals to voluntarily assume financial risk for all Medicare expenditures for 90 days after an index hospitalisation and share in savings if specific quality measures are met; and accountable care organisations, which assume responsibility for care of at least 5000 Medicare beneficiaries, and, like the bundled care programme, can share in savings when specific quality measures are met. Nursing homes can also participate in 'institutional special needs plans' which also financially incentivise better care, including reductions in $\mathrm{PAH}$ and ED visits.

What lessons can be learnt from these various programmes that may be helpful in furthering efforts to reduce PAH and ED visits in the UK as well as other countries? First, in order to improve quality, we must be able to define it. There is no well-accepted definition of PAH or avoidable ED visits in the LTCF population. Like many conditions in vulnerable older people, the causes of these events are complex and multifactorial. ${ }^{4-11}{ }^{19}$ Most definitions of PAH are based on diagnoses, 33619 including those used in the Lloyd et al study. Although the diagnoses have generally been determined by expert clinicians, it is naïve to think that all hospitalisations in this population for diagnoses such as urinary tract infection, pneumonia, heart failure and exacerbation of chronic obstructive pulmonary disease are potentially avoidable, because so many different environmental and person-centred factors can play a role in the decision to transfer a resident from an LTCF to a hospital. ${ }^{1920}$ It is, however, reasonable to expect that a substantial percentage of these transfers are, in fact, avoidable. Studies involving expert clinician review of nursing home, ED and hospital records suggest that between a third and two-thirds of these transfers are avoidable. ${ }^{24}$ Studies of several thousand root cause analyses of hospital transfers performed by nursing home staff demonstrate that, in retrospect, they consider between one in four and one in five transfers potentially avoidable. ${ }^{9-11}$ The major reasons for these transfers being rated as potentially avoidable include nursing home staff recognition that the condition could have been identified and evaluated earlier before it became severe enough to require care in an acute hospital level; that some conditions could have been feasibly and safely managed in the facility without transfer using existing resources; and that better advance care planning to avoid futile and uncomfortable hospital care at the end of life, and using palliative or hospice care instead could have prevented the hospital transfer.
The intervention implemented in the UK involved both an increase in the on-site presence of a primary care physician and nursing staff education. As described, this intervention does not seem to differ substantially from usual care in many nursing homes in USA. These resources are not as common in US assisted living facilities, which are more similar to UK residential care facilities. One of the most effective interventions for reducing hospitalisations in USA is on-site support by advance practice clinicians, including nurse practitioners and physician assistants, working in collaboration with a primary care clinician. ${ }^{21}$ Nursing staff education, on the other hand, is necessary, but not sufficient to improve clinical care. Nurses, advance practice clinicians and physicians need tools that they can use in everyday practice in addition to education that can help them provide higher quality and safer care in order to reduce PAH and ED visits.

Several such tools and programmes are now available. The American Directors Association/Society for PostAcute and Long-Term Care (AMDA) has clinical practice guidelines and tools that may be helpful in complementing and enhancing the intervention described by Lloyd et al. ${ }^{22} 23$ The Interventions to Reduce Acute Care Transfers (INTERACT) programme has over 25 quality improvement, communication, decision support and advance care planning tools that are publicly available and free for use in clinical practice and education. ${ }^{24} 25$ Robust implementation of the INTERACT tools within a quality improvement framework to proactively manage acute changes in condition has been associated with substantial reductions in all-cause hospitalisations as well as PAH. ${ }^{26-31}$ An initiative supported by the US Centers for Medicare and Medicaid Services to reduce $\mathrm{PAH}$ among long-stay nursing home residents in seven sites involving close to 140 nursing homes, demonstrated significant reductions in hospitalisations and related costs. ${ }^{32}$ Each of these seven sites received training on and implemented components of the INTERACT programme as part of their interventions. One of these sites (the Missouri Quality Initiative) used on-site nurse practitioners to assist in intervention implementation and evaluation of acute changes in condition, and demonstrated a $30 \%$ reduction in all-cause hospitalisations. $^{33} 34$ A second intervention (Optimizing Patient Transfers, Impacting Medical Quality, and Improving Symptoms) ${ }^{35} 36$ used nurse practitioners in a similar manner to implement a multifaceted intervention with a major focus on advance care planning and demonstrated $>30 \%$ reduction in $\mathrm{PAH}$.

All health policy strategies can have unintended consequences. One such consequence of efforts to reduce $\mathrm{PAH}$ and ED visits is that LTCFs may attempt to manage sicker residents without adequate infrastructure, resulting in threats to patient safety and quality. Critical infrastructure includes availability of well-trained staff, regular on-site visits by physicians or advance practice clinicians, and access to rapid turnover for laboratory 
testing and pharmacy services. Recent pressure to identify and manage 'early sepsis' in LTCFs is an example of how efforts to reduce hospital transfers may outstrip the capabilities of most facilities because this requires the availability of rapid laboratory testing, including lactic acid levels, and optimal administration of antibiotics parenterally within an hour. ${ }^{37}$ Apart from sepsis, many conditions can in fact be managed without transfer without unintended consequences. In a large-scale trial in which nursing homes were selected based on the availability of adequate resources, there was no evidence that INTERACT implementation had a negative impact on self-reported measures of quality and patient safety such as falls, dehydration and unexpected death. ${ }^{29}$ Nursing homes in this trial were able to manage a wide variety of acute changes in condition without hospital transfer in the 7 days after the initial change in condition in close to $90 \%$ of the cases they reported on. ${ }^{31}$ A second example of an unintended consequence in efforts to manage sicker residents in the LTCF is unnecessary antimicrobial use, adverse effects of these agents including diarrhoea and related complications, and the development and spread of resistant organisms within the facility and to affiliated hospitals. Efforts to reduce PAH and ED visits must therefore be coupled with implementation of intensive efforts to maintain and improve antimicrobial stewardship. ${ }^{38}$

Even in LTCFs that have adequate staffing and other resources, as well as access to education and tools to use in everyday practice, implementation of programmes to reduce $\mathrm{PAH}$ and $\mathrm{ED}$ visits is challenging. We identified a number of barriers to INTERACT implementation during our randomised trial. ${ }^{30}$ There are several strategies that may help overcome these barriers and strengthen implementation of interventions to reduce PAH in the LTCF setting, as well as many other areas for quality improvement activities. First, organisational culture must be focused on high-quality care and patient safety, and as a component of that culture, leadership must strongly and tangibly support programme implementation-including appointment of champions who have the time to facilitate and monitor intervention fidelity and outcomes. Leadership must also include strong medical direction, which is required in US nursing homes. Organisations should incentivise and support their medical directors to become certified through AMDA's well-established certification programme. Second, incentives must be aligned, especially for key drivers of LTCF behaviour, including reimbursement and regulation. ${ }^{39}$ The growth of value-based models of care, and inclusion of relevant measures of PAH and ED visits in state and federal quality rating systems are critical steps in this direction. We still have a long way to go, however, in developing and validating quality measures that will help further reduce PAH and ED visits. This is highlighted in a recent paper and editorial in this journal, which describe the lack of correlation between most existing LTCF quality measures and PAH. ${ }^{40}{ }^{41}$
Third, interventions must be embedded in everyday care practices and quality improvement activities, and not viewed as 'extra work' by LTCF staff. One approach to achieving this goal is to effectively and efficiently incorporate evidence-based clinical alerts, decision support, standardised evaluation and documentation processes, condition-specific order sets, and quality improvement tools into health information technology. ${ }^{42}$ In USA, an increasing number of LTCFs are using electronic health records for clinical, as well as financial and regulatory purposes, providing the opportunity to work towards achieving this goal. Fourth, we must continue to increase the expertise of all levels of the healthcare workforce in the care of vulnerable older who are cared for in LTCFs. The American Geriatrics Society and AMDA have developed a wide variety of opportunities, including a wealth of educational materials that are readily accessible on their websites, for physicians and advance practice clinicians who practice in LTCF settings. Telemedicine has the potential to assist LTCFs in rural and other areas where physicians and advance practice clinicians with expertise in geriatric medicine and long-term care is lacking. ${ }^{43}$

Last, but not least, we must continue to strive to provide person-centred care in our efforts to improve quality of care for this population, ${ }^{44}$ and reduce PAH and ED visits. Trusting relationships between residents and families, LTCF facility staff and primary care clinicians who have the communication skills to discuss goals of care, prognosis, reasonable expectations and match interventions with these critical factors, will go a long way to improving care and quality of life for LTCF residents, while reducing PAH, ED visits, their complications and costs.

Funding The authors have not declared a specific grant for this research from any funding agency in the public, commercial or not-for-profit sectors.

Competing interests JGO is a full-time employee of Florida Atlantic University (FAU) and has received support through FAU for research on INTERACT from the National Institutes of Health, the Centres for Medicare \& Medicaid Services, The Commonwealth Fund, the Retirement Research Foundation, the Florida Medical Malpractice Joint Underwriting

Association, PointClickCare, Medline Industries and Think

Research. JGO and his wife receive royalties from Pathway

Health, which currently holds the license. JGO serves as a paid advisor to Pathway Health, which has a license to conduct training on and sublicense the INTERACT programme. Work on funded INTERACT research is subject to the terms of Conflict of Interest Management plans developed and approved by the FAU Financial Conflict of Interest Committee.

Patient consent for publication Not required.

Provenance and peer review Commissioned; internally peer reviewed.

\section{REFERENCES}

1 Mor V, Intrator O, Feng Z, et al. The revolving door of rehospitalization from skilled nursing facilities. Health Aff 2010;29:57-64.

2 Saliba D, Kington R, Buchanan J, et al. Appropriateness of the decision to transfer nursing facility residents to the hospital. $J$ Am Geriatr Soc 2000;48:154-63. 
3 Grabowski DC, O'Malley AJ, Barhydt NR. The costs and potential savings associated with nursing home hospitalizations. Health Affairs 2007;26:1753-61.

4 Ouslander JG, Lamb G, Perloe M, et al. Potentially avoidable hospitalizations of nursing home residents: frequency, causes, and costs. J Am Geriatr Soc 2010;58:627-35.

5 Ouslander JG, Berenson RA. Reducing unnecessary hospitalizations of nursing home residents. N Engl J Med 2011;365:1165-7.

6 Walsh EG, Wiener JM, Haber S, et al. Potentially avoidable hospitalizations of dually eligible Medicare and Medicaid beneficiaries from nursing facility and Home- and community-based services waiver programs. J Am Geriatr Soc 2012;60:821-9.

7 Burke RE, Rooks SP, Levy C, et al. Identifying potentially preventable emergency department visits by nursing home residents in the United States. J Am Med Dir Assoc 2015;16:395-9.

8 Ouslander JG, Schnelle JF, Han J. Is this really an emergency? reducing potentially preventable emergency department visits among nursing home residents. J Am Med Dir Assoc $2015 ; 16: 354-7$.

9 Ouslander JG, Naharci I, Engstrom G, et al. Root cause analyses of transfers of skilled nursing facility patients to acute hospitals: lessons learned for reducing unnecessary hospitalizations. J Am Med Dir Assoc 2016;17:256-62.

10 Ouslander JG, Naharci I, Engstrom G, et al. Lessons learned from root cause analyses of transfers of skilled nursing Facility (SNF) patients to acute hospitals: transfers Rated as preventable vs. Non-Preventable by snf staff. J Am Med Dir Assn 2016;17:256-62.

11 Ouslander JG, Naharci I, Engstrom G, et al. Hospital Transfers of Skilled Nursing Facility (SNF) Patients Within 48 Hours and 30 Days After SNF Admission. J Am Med Dir Assoc 2016;17:839-45.

12 Vasilevskis EE, Ouslander JG, Mixon AS, et al. Potentially avoidable readmissions of patients discharged to post-acute care: perspectives of hospital and skilled nursing facility staff. $J$ Am Geriatr Soc 2017;65:269-76.

13 Lloyd T, Conti S, Santos F, et al. Effect on secondary care of providing enhanced support to residential and nursing home residents: a subgroup analysis of a retrospective matched cohort study. BMJ Qual Saf 2019;28:534-7.

14 Zimmer JG, Eggert GM, Treat A, et al. Nursing homes as acute care providers a pilot study of incentives to reduce hospitalizations. J Am Geriatr Soc 1988;36:124-9.

15 Ouslander JG. Reducing the hospitalization of nursing home residents. J Am Geriatr Soc 1988;36:171-3.

16 LaMantia MA, Scheunemann LP, Viera AJ, et al. Interventions to improve transitional care between nursing homes and hospitals: a systematic review. J Amer Geriatr Soc 2010;58:777-82.

17 Brock J, Mitchell J, Irby K, et al. Association between quality improvement for care transitions in communities and rehospitalizations among Medicare beneficiaries. JAMA 2013;309:381-91.

18 Centers for Medicare \& Medicaid Services (CMS). Hospital readmissions reduction program. Available: https://www. cms.gov/medicare/medicare-fee-for-service-payment/ acuteinpatientpps/readmissions-reduction-program.html [Accessed 24 Mar 2019].
19 Ouslander JG, Maslow K. Geriatrics and the triple aim: defining preventable hospitalizations in the long-term care population. J Am Geriatr Soc 2012;60:2313-8.

20 Unroe KT, Carnahan JL, Hickman SE, et al. The complexity of determining whether a nursing home transfer is avoidable at time of transfer. J Am Geriatr Soc 2018;66:895-901.

21 Konetzka RT, Spector W, Limcangco MR. Reducing hospitalizations from long-term care settings. Medical Care Research and Review 2008;65:40-66.

22 American Medical Directors Association. Transitions of care in the long-term care continuum clinical practice guideline. Columbia, MD: AMDA, 2010.

23 AMDA. Resources. Available: https://paltc.org/resources [Accessed 8 May 2019].

24 Ouslander JG, Bonner A, Herndon L. The interact quality improvement program: an overview for medical directors and primary care clinicians in long-term care. J Amer Med Dir Assn 2014;15:162-70.

25 Pathway Health Services. Available: https://www.interactpathway.com/ [Accessed 24 Mar 2019].

26 Ouslander JG, Lamb G, Tappen R, et al. Interventions to reduce hospitalizations from nursing homes: evaluation of the interact II collaborative quality improvement project. J Amer Geriatr Soc 2011;59:745-53.

27 Kane RL, Huckfeldt P, Tappen R, et al. Effects of an intervention to reduce hospitalizations from nursing homes: a randomized implementation trial of the interact program. JAMA Intern Med 2017;177:1257-64.

28 Huckfeldt PJ, Kane RL, Yang Z, et al. Degree of implementation of interact quality improvement program associated with reduced hospitalizations. J Am Geriatr Soc 2018;66:1830-7.

29 Tappen RM, Newman D, Huckfeldt P, et al. Evaluation of nursing facility resident safety during implementation of the interact quality improvement program. J Am Med Dir Assoc 2018;19:907-13.

30 Tappen RM, Wolf DG, Rahemi Z, et al. Barriers and facilitators to implementing a change initiative in long-term care using the INTERACT ${ }^{\circledR}$ quality improvement program. Health Care Manag 2017;36:219-30.

31 Ouslander JG, Engstrom G, Reyes B, et al. Management of acute changes in condition in skilled nursing facilities. $\mathrm{J} \mathrm{Am}$ Geriatr Soc 2018;66:2259-66.

32 Ingber MJ, Feng Z, Khatutsky G, et al. Initiative to reduce avoidable hospitalizations among nursing facility residents shows promising results. Health Affairs 2017;36:441-50.

33 Rantz MJ, Popejoy L, Vogelsmeier A, et al. Successfully reducing hospitalizations of nursing home residents: results of the Missouri quality initiative. J Am Med Dir Assoc 2017;18:960-6.

34 Nursing Home Help. MOQI initiative. Available: https:/ nursinghomehelp.org/moqi-initiative/ [Accessed 8 May 2019].

35 Unroe KT, Nazir A, Holtz LR, et al. The optimizing patient transfers, impacting medical quality, and improving symptoms: transforming institutional care approach: Preliminary data from the implementation of a centers for Medicare and Medicaid Services nursing facility demonstration Project. J Am Geriatr Soc 2015;63:165-9.

36 Available: https://www.optimistic-care.org/ [Accessed May 8, 2019].

37 Reyes BJ, Chang J, Vaynberg L, et al. Early identification and management of sepsis in nursing facilities: challenges and opportunities. J Am Med Dir Assoc 2018;19:465-71. 
38 Jump RLP, Gaur S, Katz MJ, et al. Template for an Antibiotic Stewardship Policy for Post-Acute and Long-Term Care Settings. J Am Med Dir Assn 2017;18:913-20.

39 Zarowitz BJ, Resnick B, Ouslander JG. Quality clinical care in nursing facilities. J Am Med Dir Assn 2018;19:833-9.

$40 \mathrm{Xu}$ D, Kane R, Arling G. Relationship between nursing home quality indicators and potentially preventable hospitalisation. BMJ Qual Saf 2019;28:524-33.

41 Burke RE, Werner RM. Quality measurement and nursing homes: measuring what matters. BMJ Qual Saf 2019;28:520-3.
42 Handler S, Sharkey S, Hudak S, et al. Incorporating interact II clinical decision support tools into nursing home health information technology. Annals of Long Term Care and Aging 2011;19:23-6.

43 Grabowski DC, O'Malley AJ. Use of telemedicine can reduce hospitalizations of nursing home residents and generate savings for Medicare. Health Affairs 2014;33:244-50.

44 American Geriatrics Society Expert Panel on Person-Centered Care. A definition and essential elements. J Amer Geriatr Soc 2016;64:15-18. 